\title{
Article \\ Transcriptome Characterization of the Roles of Abscisic Acid and Calcium Signaling during Water Deficit in Garlic
}

\author{
Guang-Long Wang ${ }^{1,2, *}$, Ling-Yi Liu ${ }^{2}$, Qi-Zhang Wang ${ }^{1}$, Xu-Qin Ren ${ }^{2}$, Ai-Sheng Xiong ${ }^{3}{ }^{\mathbb{D}}$ and Jie Tian ${ }^{1, *}$ \\ 1 Qinghai Key Laboratory of Vegetable Genetics and Physiology, Academy of Agriculture and Forestry Sciences of \\ Qinghai University (Qinghai Academy of Agriculture and Forestry Sciences), Xining 810016, China; \\ 19095131270@qhu.edu.cn \\ 2 School of Life Science and Food Engineering, Huaiyin Institute of Technology, Huaian 223003, China; \\ liulingyi2060@163.com (L.-Y.L.); jsrxq@hyit.edu.cn (X.-Q.R.) \\ 3 State Key Laboratory of Crop Genetics and Germplasm Enhancement, College of Horticulture, \\ Nanjing Agricultural University, Nanjing 210095, China; xiongaisheng@njau.edu.cn \\ * Correspondence: guanglongwang@hyit.edu.cn (G.-L.W.); 2015990094@qhu.edu.cn (J.T.)
}

Citation: Wang, G.-L.; Liu, L.-Y.;

Wang, Q.-Z.; Ren, X.-Q.; Xiong, A.-S.; Tian, J. Transcriptome

Characterization of the Roles of

Abscisic Acid and Calcium Signaling during Water Deficit in Garlic. Appl. Sci. 2022, 12, 2440. https://doi.org/ 10.3390/app12052440

Academic Editor: Huasen Wang

Received: 13 August 2021

Accepted: 22 February 2022

Published: 26 February 2022

Publisher's Note: MDPI stays neutral with regard to jurisdictional claims in published maps and institutional affiliations.

Copyright: (C) 2022 by the authors. Licensee MDPI, Basel, Switzerland. This article is an open access article distributed under the terms and conditions of the Creative Commons Attribution (CC BY) license (https:// creativecommons.org/licenses/by/ $4.0 /)$.

\begin{abstract}
Garlic (Allium sativum L.) is one of the most important vegetable crops, and breeding drought-tolerant varieties is a vital research goal. However, the underlying molecular mechanisms in response to drought stress in garlic are still limited. In this study, garlic seedlings were subjected to 15\% PEG6000 for 0, 1, 4, and $12 \mathrm{~h}$, respectively, to simulate drought stress. Changes of transcriptomes as a result of drought stress in garlic leaves were determined by de novo assembly using the Illumina platform. In total, 96,712 unigenes and 11,936 differentially expressed genes (DEGs) were identified in the presence of drought conditions. Transcriptome profiling revealed that the DEGs were mainly enriched in the biosynthesis of secondary metabolites, MAPK signaling pathway, starch and sucrose metabolism, phenylpropanoid biosynthesis, and plant hormone signal transduction. Genes involved in abscisic acid and calcium signaling were further investigated and discussed. Our results indicated that a coordinated interplay between abscisic acid and calcium is required for drought-induced response in garlic.
\end{abstract}

Keywords: drought stress; abscisic acid; calcium signaling; RNA sequencing; garlic

\section{Introduction}

Crop growth and yield production are vulnerable to environmental stresses, such as water, cold and salt [1-3]. Among them, water deficit is one of the critical factors that lead to severe plant yield reductions, especially in arid and semi-arid regions [4,5]. It is estimated that the global temperature will continue to rise unless greenhouse gas emissions are significantly reduced [6]. That is to say, the situation of drought stress is likely to get worse. Breeding drought-resistant crops is one of the major solutions to deal with water deficit. However, a comprehensive understanding of the molecular mechanisms underlying drought tolerance in crops is the primary step if germplasm with enhanced drought resistance is to be created.

Plants suffer drought stress either when the water absorption in the roots is weak or when the leaf transpiration is very active. Water stress usually results in a series of responses at the biochemical and physiological levels in plants, including photosynthesis impediment [7], stomatal closure [8], and altered turgor pressure [9]. It can almost affect the whole process of plant growth and development, such as seed germination [10], flowering [11], and fruit development [12]. In addition, water deficit may induce the generation and accumulation of reactive oxygen species (ROS) within plants, thereby bringing about oxidative stress [13]. Previous studies were implemented to explore the gene expression patterns under water deficit in some plant species, such as Arabidopsis thaliana [14], tomato [15], mung bean [16], maize [17], and apricot [18]. Genes involved in water deficit can be 
classified into two categories in light of their functions. The first group of stress-induced transcripts is related to cell protection and the signal transduction pathway regulation, such as reactive oxygen species-scavenging genes, hormone response, water channel proteins, photosynthesis-related proteins, and heat shock proteins $[19,20]$. The latter gene group under water stress in plants consists of transcription factors and dehydration-responsive elements, which take part in further regulation of signal transduction and stress-responsive gene expression [21,22].

Nowadays, research regarding plant biology, biotechnology, and molecular biology requires mass data for the identification of the cellular state, physiology, and activity. Transcriptome analysis using next-generation sequencing can provide information about gene expression, alternative splicing, single nucleotide variation, and fusion gene detection in large quantities, which are extremely important in unsequenced organisms [23]. By now, transcriptome technology has been widely used in identifying water deficit-related genes in numerous plant species, and a deep understanding of the molecular mechanisms underlying water stress response has been achieved.

Garlic (Allium sativum L.), a member of the Liliaceae family, is considered to be one of the most important vegetables worldwide with a harvested area of 834,226 ha and an annual production of 23,305,888 tonnes in China (FAO, 2019). Garlic is commonly used as a raw vegetable for culinary purposes. It is also popular in traditional and modern medicines, owing to its therapeutic and medicinal effects [24,25]. Garlic plants usually experience water stress during the period of growth and development, leading to decreased yield and quality. Abscisic acid and calcium signaling have been demonstrated to contribute to plant response to drought stress in many plants [26,27]. However, there is limited information about the response of garlic plants under water stress at the molecular level. Therefore, it is unknown whether abscisic acid and calcium could get involved in the process in garlic.

Our study aimed to identify genes in polyethylene glycol 6000 (PEG6000)-simulated drought stress by the Illumina HiSeq platform. Here, we investigated (1) how gene expression varied at different treatment times with respect to the well-watered conditions and (2) the role of abscisic acid and calcium signaling pathways in garlic plants' response to water stress. The results from this study would provide genetic resources about garlic plants exposed to water deficit and contribute to breeding aimed at improving garlic resistance against water stress.

\section{Materials and Methods}

\subsection{Plant Materials and Experimental Design}

Garlic cloves of 'Siliuban', a variety with four to six cloves, were used as material in this work. 'Siliuban' is widely cultivated in China due to its spicy taste. Garlic cloves were sown in a pot filled with vermiculite and organic soil $(\mathrm{v}: \mathrm{v}, 1: 1)$ in a greenhouse in Huaiyin Institute of Technology $\left(33^{\circ} 32^{\prime} \mathrm{N}, 119^{\circ} 01^{\prime} \mathrm{E}\right)$. The temperature was maintained at $22{ }^{\circ} \mathrm{C} / 18{ }^{\circ} \mathrm{C}$ (day/night) with a relative humidity of $75 \%$. After $16 \mathrm{~d}$, the garlic seedlings were transferred to a hydroponic tank, and the nutrient solution was Hoagland nutrient solution $\left(6 \mathrm{mM} \mathrm{KNO}_{3}, 4 \mathrm{mM} \mathrm{Ca}\left(\mathrm{NO}_{3}\right)_{2} \cdot 4 \mathrm{H}_{2} \mathrm{O}, 2 \mathrm{mM} \mathrm{MgSO}_{4} \cdot 7 \mathrm{H}_{2} \mathrm{O}, 1 \mathrm{mM} \mathrm{NH} \mathrm{H}_{2} \mathrm{PO}_{4}\right.$, $45 \mu \mathrm{M} \mathrm{H}_{3} \mathrm{BO}_{3}, 10 \mu \mathrm{M} \mathrm{MnSO}_{4} \cdot 4 \mathrm{H}_{2} \mathrm{O}, 0.8 \mu \mathrm{M} \mathrm{ZnSO}_{4} \cdot 7 \mathrm{H}_{2} \mathrm{O}, 0.3 \mu \mathrm{M} \mathrm{CuSO} \cdot \cdot 5 \mathrm{H}_{2} \mathrm{O}, 0.02 \mu \mathrm{M}$ $\left(\mathrm{NH}_{4}\right)_{6} \mathrm{Mo}_{7} \mathrm{O}_{24} \cdot 4 \mathrm{H}_{2} \mathrm{O}, 50 \mu \mathrm{M} \mathrm{Na}$-EDTA, and $\left.50 \mu \mathrm{M} \mathrm{FeSO} \cdot \cdot 7 \mathrm{H}_{2} \mathrm{O}\right)$. The $\mathrm{pH}$ value of the solution was adjusted to 6.0, and the electrical conductivity of nutrient solution was $2.0 \mathrm{~ms} \cdot \mathrm{cm}^{-1}$. Seven days later, the garlic plants were treated with simulated drought stress (15\% PEG6000) for 0 (D0), 1 (D1), 4 (D4), and 12 (D12) h. Each treatment was performed with three independent biological replicates. Garlic leaves, roots, and cloves were harvested, immediately frozen in liquid nitrogen, and stored at $-80^{\circ} \mathrm{C}$ for further analysis.

\subsection{Total RNA Isolation and Library Construction for Illumina Sequencing}

Total RNA was extracted from a pool of three independent biological replicates, each comprising approximately $0.2 \mathrm{~g}$ leaf samples. An ethanol precipitation protocol and the CTAB-PBIOZOL reagent were introduced to extract and purify the total RNA from garlic 
leaves according to the manual instructions. Total RNA was qualified and quantified by determining the optical density at 260 and $280 \mathrm{~nm}$ with a Nano Drop instrument (NanoDrop Technologies, Wilmington, DE, USA). Magnetic oligo-dT beads were utilized to purify mRNA. The sublimated mRNA was then broken into short pieces under high temperature conditions. The first-strand cDNA was synthesized by using a first strand reaction system, and the second-strand cDNA was synthesized as well. The reaction product was purified, and sticky ends were repaired. Afterwards, the base " $\mathrm{A}$ " was added to the $3^{\prime}$ end of the cDNA, and the adapter was connected. The cDNA segments with adapters were propagated by PCR. The library quality and quantity were measured by using the Agilent 2100 bioanalyzer and quantitative real-time PCR (qRT-PCR). The cDNA library qualified was sequenced on an Illumina HiSeq 4000 platform with a 150-bp paired-end approach. The Bioproject accession number of the transcriptome data was PRJNA799598 in the NCBI Short Read Archive (SRA) database.

\subsection{Assembly of Clean Reads and Functional Annotation}

The quality parameters of raw and filtered read sets were checked for each sample using FastQC [28]. The resulting raw reads were filtered with SOAPnuke (v1.4.0) [29] to remove the sequencing adapter, low-quality base, and unknown $(\mathrm{N})$ base. Trinity [30] and Tgicl [31] software programs were applied to assemble the clean reads, carry out clustering, eliminate redundant data, and obtain unique genes. Trinity was carried out under the default settings ( $25 \mathrm{~K}$-mer). The completeness of the transcriptome assembly of garlic was assessed using BUSCO v3.0.2 [32]. Functional annotation of unigenes was performed by comparing genes with NT (http:/ / ftp.ncbi.nlm.nih.gov/blast/db (accessed on 3 July 2019)), NR (http:/ /ftp:/ / ftp.ncbi.nlm.nih.gov/blast/db (accessed on 3 July 2019)), KOG [33], KEGG [34], and SwissProt (http:/ / ftp.ebi.ac.uk/pub / databases / swissprot (accessed on 3 July 2019)) databases using the software BLAST [35], whereas GO [36] annotation was conducted by Blast2GO [37] software.

\subsection{Identification of Differentially Expressed Unigenes}

Clean reads were mapped to the assembled unique genes by Bowtie2 (v2.2.5) [38]. Gene expression profiles were analyzed by RSEM [39] and expressed by fragments per kilo base of transcript per million mapped reads (FPKM) values. PossionDis [40] was utilized to analyze differentially expressed genes (DEGs), and unigenes with Log2 fold change $\geq 1$ or $\leq-1$ and false discovery rate (FDR) $<0.001$ were considered to be DEGs. KEGG pathway enrichment analysis was carried out to further understand the annotated DEGs.

\section{5. $q R T-P C R$ Verification}

The total RNA from different treatments was collected to generate first-strand cDNA with a HiScript 1st Strand cDNA Synthesis Kit (Vazyme, Nanjing, China) in accordance with the manufacturer's instructions. The cDNA was diluted 15 -fold, and $2 \mu \mathrm{L}$ was taken for qRT-PCR reaction in a $20 \mu \mathrm{L}$ reaction volume. The reaction mixture contained $10 \mu \mathrm{L}$ of ChamQ SYBR qPCR Master Mix (Vazyme, Nanjing, China), 7.2 $\mu \mathrm{L}$ of deionized water, $2 \mu \mathrm{L}$ of cDNA template, and $0.4 \mu \mathrm{L}$ of each primer. To determine whether abscisic acid and calcium signaling could get involved in drought stress in garlic, differentially expressed genes involved in abscisic acid and calcium signaling were selected for qRT-PCR validation. The primers (Table 1) for qRT-PCR experiments were generated based on Primer Premier 6.0 software. Transcript levels of the selected genes were determined on a CFX96 Real-Time PCR Detection System (Bio-Rad, Foster city, CA, USA). The relative gene expression levels were normalized against the internal reference gene SAND [41]. 
Table 1. Summary of Illumina RNA-sequencing data.

\begin{tabular}{cccccc}
\hline Samples & Raw Reads & Clean Reads & Q20 (\%) & Unigenes & $\begin{array}{c}\text { GC Content } \\
(\mathbf{\%})\end{array}$ \\
\hline D0 & $40,195,832$ & $40,188,220$ & 97.05 & 67,818 & 40.19 \\
D1 & $41,271,878$ & $41,264,246$ & 97.09 & 65,943 & 40.36 \\
D4 & $40,895,002$ & $40,887,022$ & 97.09 & 64,215 & 40.28 \\
D12 & $40,963,138$ & $40,955,782$ & 97.03 & 62,359 & 40.53 \\
\hline
\end{tabular}

\subsection{Statistical Analysis}

Data collected from qRT-PCR were subjected to analysis of variance (ANOVA), followed by Duncan's multiple range test, using SPSS 16.0 (SPSS, Chicaga, IL, USA) software. The significance level was set at $p<0.05$.

\section{Results}

\subsection{RNA Sequencing}

Garlic samples from different water stress treatments were exposed to Illuminabased RNA-Seq. The detailed sequencing results are displayed in Table 1. After filtering, 40,188,220, 41,264,246, 40,887,022, and 40,955,782 clean reads were obtained from the water deficit treatments, which were then assembled into $67,818,65,943,62,359$, and 64,215 unigenes, respectively. BUSCO analysis revealed great completeness of the assembly (Figure S1). There were 32,091,884 (79.85\%), 33,873,994 (82.09\%), 33,316,246 (81.48\%), and $32,943,202(80.44 \%)$ total mapped reads in each sample, respectively. The GC content of the unigenes in each treatment ranged from $40.19 \%$ to $40.53 \%$.

A total of 96,712 unigenes were gained in the general library with a mean length of $803 \mathrm{bp}$ and an N50 length of $1301 \mathrm{bp}$. The unigenes were annotated against NR, NT, SwissProt, KOG, KEGG, GO, and Pfam functional databases, and 28,014 (28.97\%), 4493 (4.65\%), $19,174(19.83 \%), 31,955(33.04 \%), 18,920(19.56 \%), 11,801(12.20 \%)$, and 27,195 (28.12\%) unigenes obtained functional annotation, respectively. Approximately 31,404 predicted coding sequences (CDSs) were generated from Transdecoder software, and their length distribution is shown in Figure 1.

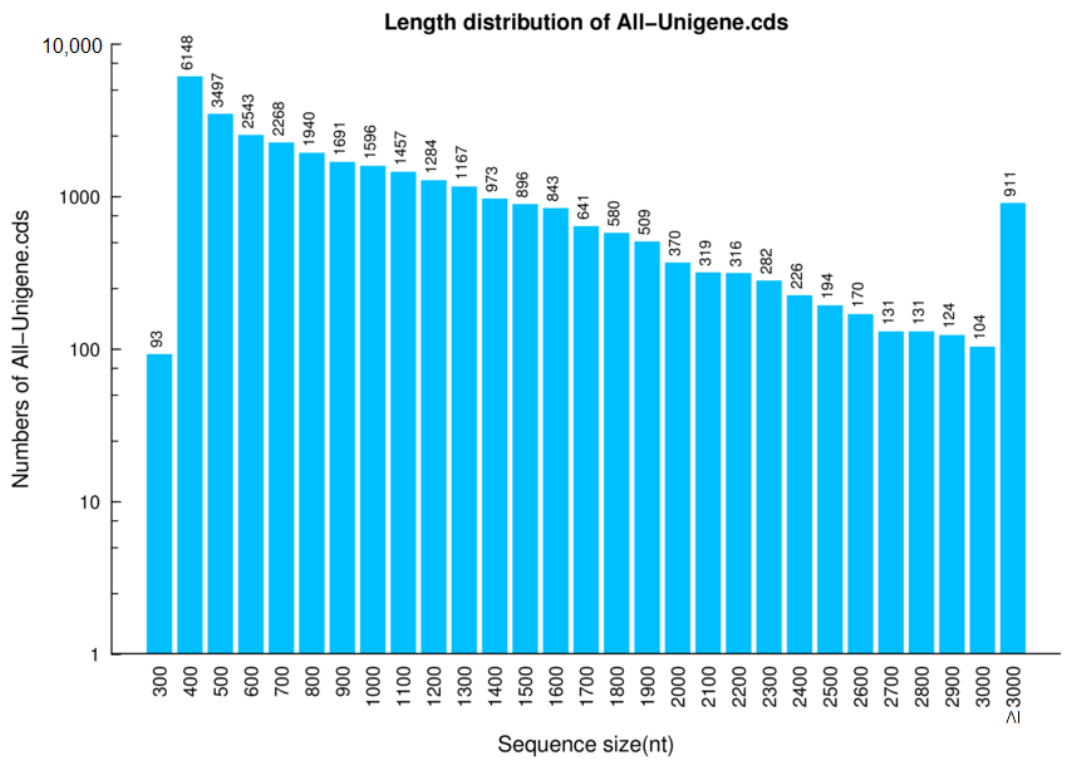

Figure 1. Length distribution of the unigene coding sequences generated from Transdecoder.

As for species distribution, $36.9 \%$ of the 96,712 unigenes have high similarity to genes from Asparagus officinalis, followed by Elaeis guineensis (7.6\%), Phoenix dactylifera (5.12\%), and Ananas comosus (2.95\%) (Figure S2). 


\subsection{Functional Annotation and Classification}

The GO (gene ontology) category was carried out to functionally classify garlic transcriptome unigenes using Blast2GO. Among the 96,712 annotated unigenes, 11,801 (12.20\%) unigenes were categorized into three main GO terms and 63 subterms (Figure S3). The unigene number in the "cellular process" and "metabolic process" slims was the largest in the biological process category, whereas "cell" and "cell part" occupied the most represented groups in the cellular component category. In the molecular function category, "binding" and "catalytic activity" accounted for the most enriched groups (Figure S3).

The unigenes were mapped to KOG (clusters of eukaryotic orthologous groups), including orthologous proteins of seven complete eukaryotic genomes. Totally, 31,955 unigenes were assigned to 4 main categories and 25 subcategories (Figure S4). In the cellular processes and signaling group, the cluster "signal transduction mechanisms" was the largest in number, whereas "transcription" was the most enriched in the information storage and processing category. "Carbohydrate transport and metabolism" accounted for the largest proportion of all metabolism subcategories, followed by "lipid transport and metabolism" and "energy production and conversion".

The KEGG (Kyoto Encyclopedia of Genes and Genomes) database was applied to identify the unigene functions, and 18,920 unigenes were classified into five groups. The five most enriched subgroups were "global and overview maps", "carbohydrate metabolism", "translation", "folding, sorting and degradation", and "amino acid metabolism" (Figure S5).

\subsection{Characterization of Differentially Expressed Genes}

To characterize the differentially expressed unigenes during the period of water deficit process, comparison of the transcript levels of assembled unigenes among the four samples (D0, D1, D4, and D12) was performed. There were 1308, 1452, 2152, 908, 1608, and 1484 up-regulated and 2196, 2647, 4866, 1060, 2922, and 2197 down-regulated unigenes observed in "D0 vs. D1", “D0 vs. D4", “D0 vs. D12", "D1 vs. D4", “D1 vs. D12", and "D4 vs. D12" comparisons, respectively (Figures 2 and 3). Totally, 11,936 differentially expressed unigenes were detected, which was about 12.34 percent of all unigenes assembled. Based on KEGG pathway enrichment analysis, the differentially expressed unigenes with pathway annotation were mainly involved in the biosynthesis of secondary metabolites, MAPK signaling pathway, starch and sucrose metabolism, phenylpropanoid biosynthesis, and plant hormone signal transduction (Figure 4).

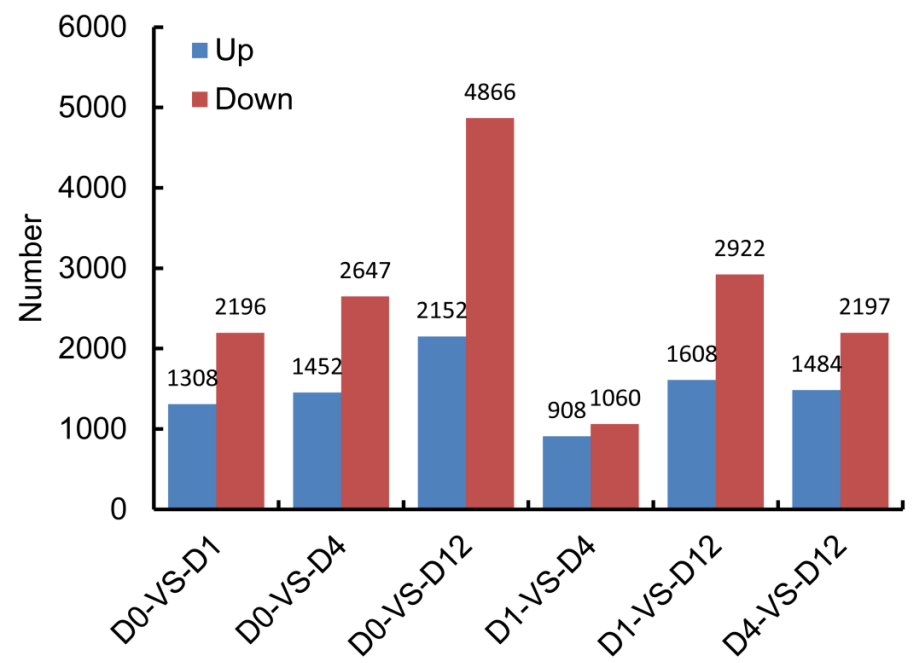

Figure 2. Comparison of DEGs between drought-treated samples. 

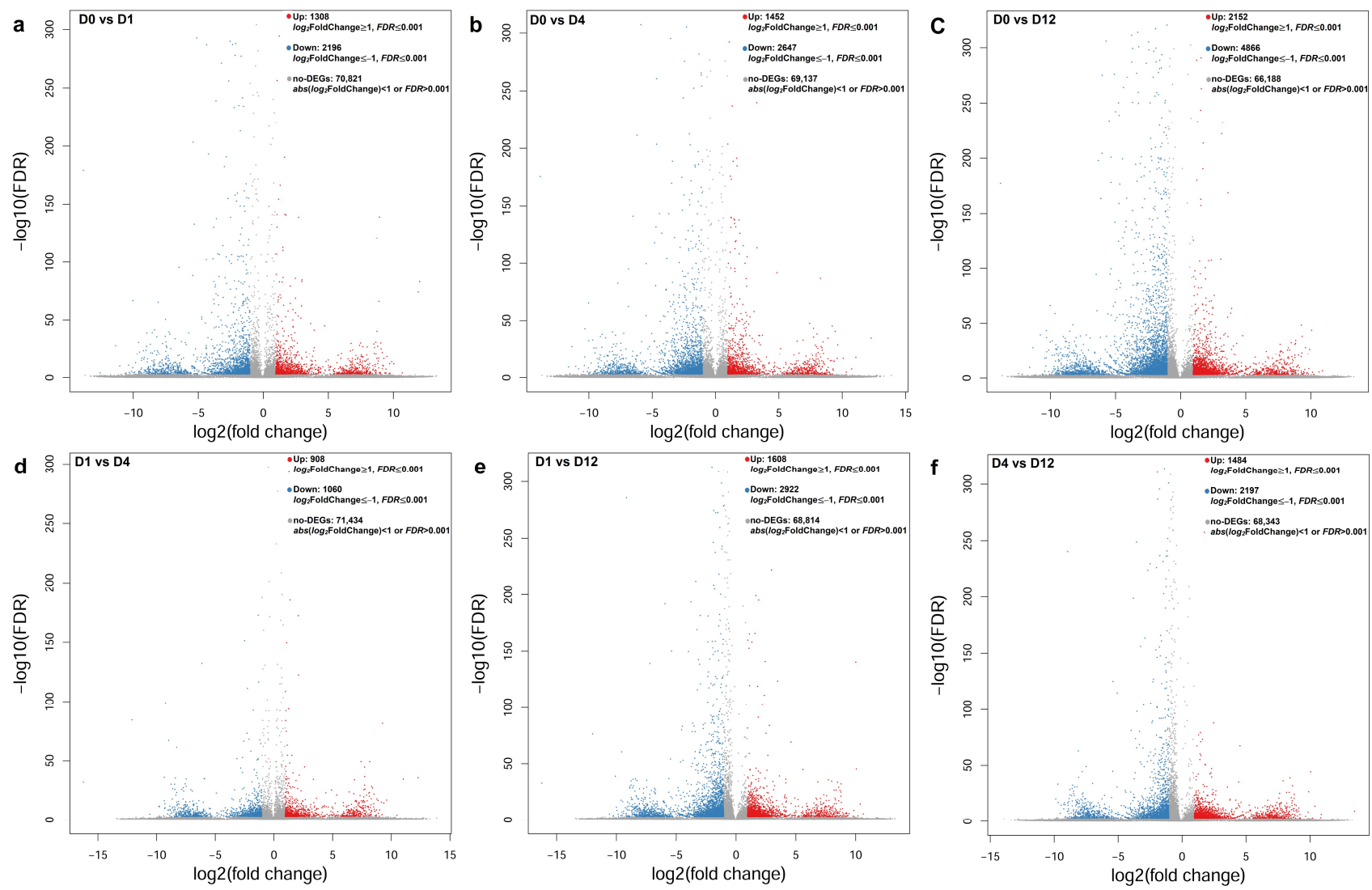

Figure 3. Distribution of the differentially expressed genes between drought-stressed samples. (a) Volcano plot of DEGs between D0 and D1 samples. (b) Volcano plot of DEGs between D0 and D4 samples. (c) Volcano plot of DEGs between D0 and D12 samples. (d) Volcano plot of DEGs between D1 and D4 samples. (e) Volcano plot of DEGs between D1 and D12 samples. (f) Volcano plot of DEGs between D4 and D12 samples.

\subsection{Validation of Genes Related to Abscisic Acid Metabolism and Signaling}

In the abscisic acid metabolism and signaling pathway, the expression levels of 8 genes including 9-cis-epoxycarotenoid dioxygenase (Unigene21708_All), violaxanthin de-epoxidase (CL3990.Contig2_All), xanthoxin dehydrogenase (Unigene30770_All), beta-carotene hydroxylase (Unigene15097_All), abscisic acid 8'-hydroxylase (CL9408.Contig2_All), ABA responsive element binding factor (CL3543.Contig1_All), abscisic acid receptor PYL4-like (Unigene19549_All), and protein phosphatase 2C (CL3509.Contig2_All) were detected by qRT-PCR (Figure 5). In the leaves, the transcript levels of these genes were correlated well with the digital gene expression patterns (Tables S1 and S2). The two genes, Unigene21708_All and CL3543.Contig1_All, both possessed the highest and lowest expression at 4 and $12 \mathrm{~h}$ after simulated drought stress, respectively. Transcription of violaxanthin de-epoxidase did not change significantly after treatment for $4 \mathrm{~h}$, followed by a downward trend afterwards. The gene, Unigene3077_All, encoding xanthoxin dehydrogenase, showed a continuous rise in mRNA abundance during salt treatment, whereas expression patterns of Unigene 15097_All and CL9408.Contig2_All were completely the opposite. Unigen19549_All exhibited a downward trend in transcript levels during treatment for $4 \mathrm{~h}$. CL3509.Contig2_All was highly expressed at 4 and $12 \mathrm{~h}$ after treatment. In the cloves, Unigene21708_All and CL3509.Contig2_All were highly expressed after treatment for $4 \mathrm{~h}$, whereas CL3990.Contig2_All, Unigene 30770_All, and Unigene 19549_All showed higher mRNA abundance after treatment for $1 \mathrm{~h}$. Unigene 15097_All displayed the highest and lowest expression at 12 and $4 \mathrm{~h}$ after treatment, respectively. CL9408.Contig2_All remained relatively stable expression during the first three stages of treatment, followed 
by a sharp increase after treatment for $12 \mathrm{~h}$. Salt treatment significantly reduced the transcript levels of CL3543.Contig1_All. In the roots, Unigene21708_All, Unigene15097, and Unigene19549_All were highly expressed in the plants without treatment, whereas CL9408.Contig2_All and CL3509.Contig2_All showed the highest expression after treatment for 12 h. CL3990.Contig2_All and CL3543.Contig1_All were highly expressed at $4 \mathrm{~h}$ after treatment. Transcription of Unigene30770_All increased initially, followed by a decrease (Figure 5).

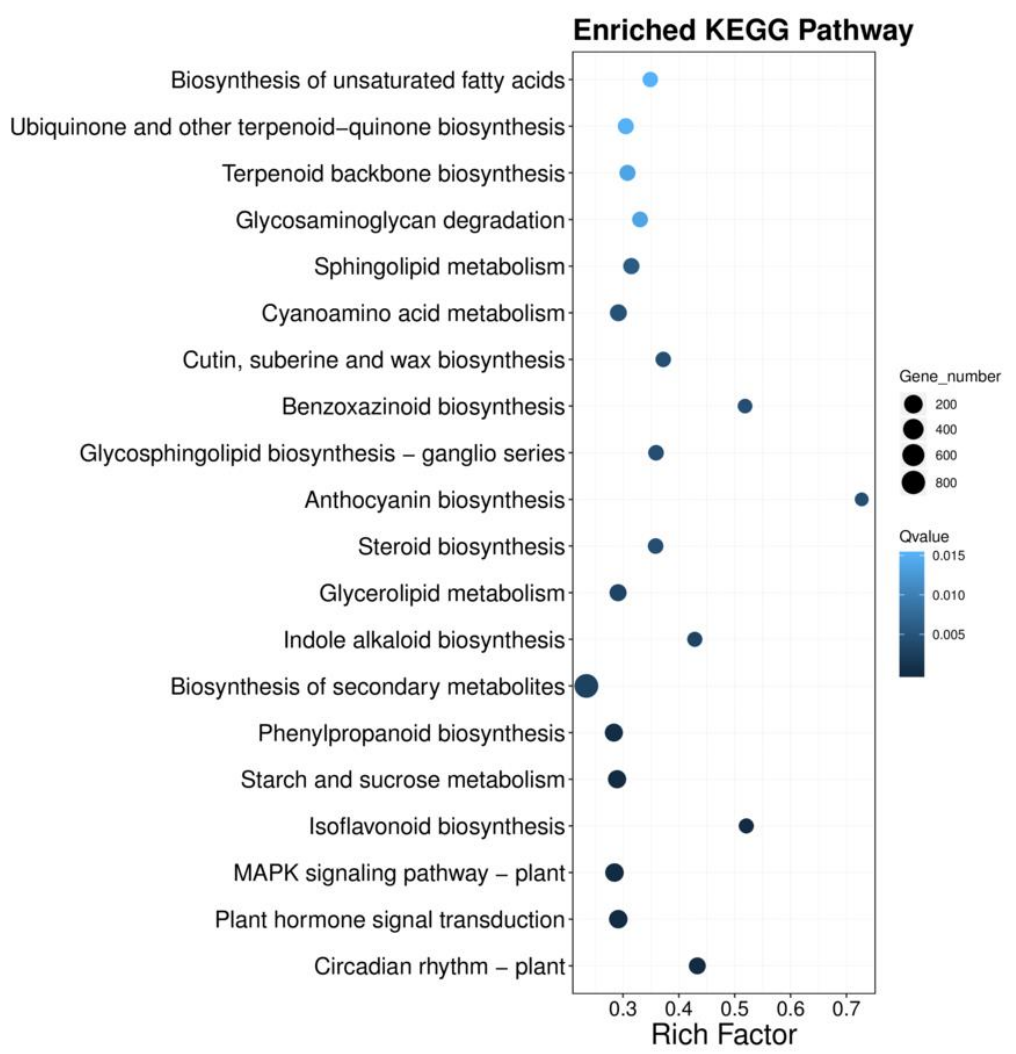

Figure 4. KEGG enrichment of differentially expressed genes under drought conditions. The $y$-axis represents the KEGG pathway, and the $x$-axis represents the enrichment factor. A high q-value is expressed by light blue, whereas a low q-value is represented by dark blue.
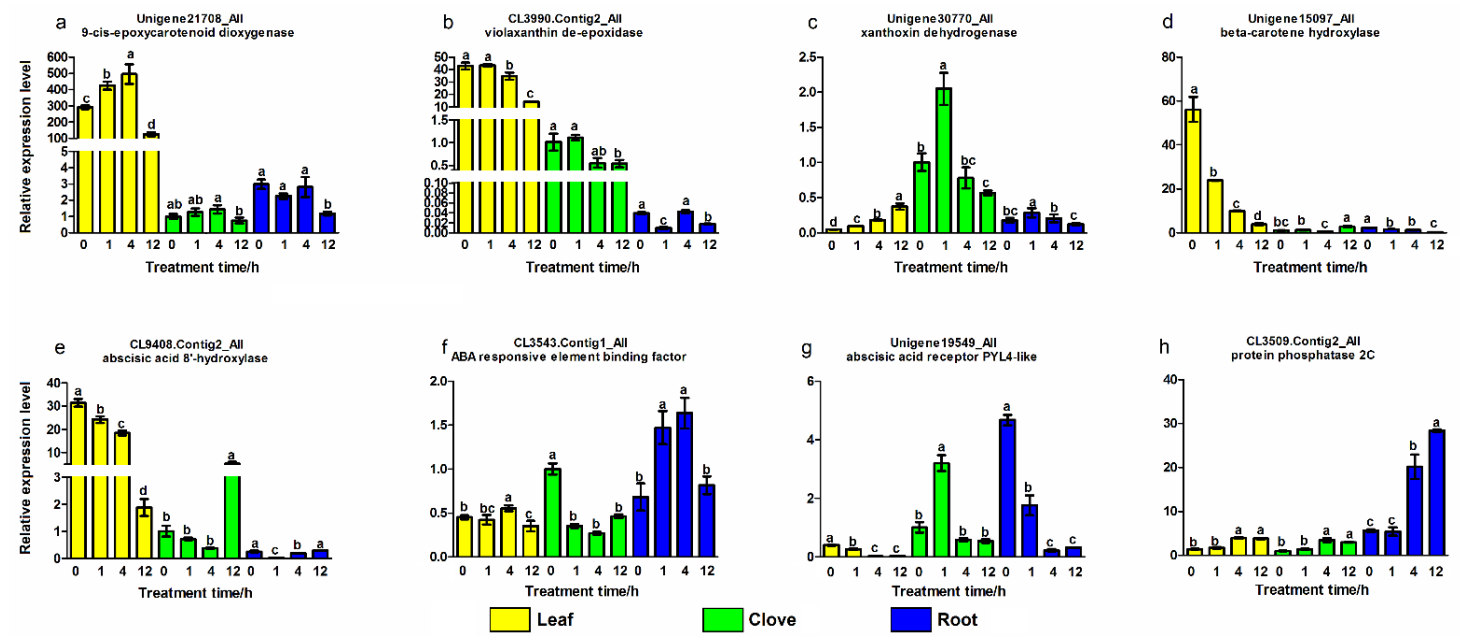

Figure 5. Expression patterns of eight genes involved in abscisic acid metabolism and signaling in garlic samples subjected to drought stress. Genes implicated in abscisic acid metabolism and signaling 
pathway include (a) 9-cis-epoxycarotenoid dioxygenase (Unigene21708_All), (b) violaxanthin deepoxidase (CL3990.Contig2_All), (c) xanthoxin dehydrogenase (Unigene30770_All), (d) beta-carotene hydroxylase (Unigene15097_All), (e) abscisic acid 8'-hydroxylase (CL9408.Contig2_All), (f) ABA responsive element binding factor (CL3543. Contig1_All), (g) abscisic acid receptor PYL4-like (Unigene19549_All), and (h) protein phosphatase 2C (CL3509.Contig2_All). The different lowercase letters in the same tissue represent a significant difference at the 0.05 level.

\subsection{Validation of Genes Related to Calcium Signaling Pathway}

The expression levels of 12 genes involved in the calcium signaling pathway were also verified (Figure 6). Transcription of most genes in the leaves correlated well with the digital genes' expression detected by RNA sequencing (Tables S3 and S4). In the leaves, the expression of calcium-dependent protein kinase 26 (CDPK26) kept on increasing until $4 \mathrm{~h}$ after treatment, followed by a significant decrease. Transcription of calcium-binding protein CML35 (CML35) showed an increase after treatment for $1 \mathrm{~h}$ and remained relatively stable at $4 \mathrm{~h}$, followed by an obvious increase again. The expression of $C B L$-interacting serine/threonine-protein kinase 4 (CIPK4), potassium channel AKT2 (AKT2), NADH/NADPH oxidase increased to a high level after treatment for $1 \mathrm{~h}$ and decreased ever since. Calcineurin $B$-like protein 3 (CBL3) and potassium channel KAT1 (KAT1) were highly expressed in the plants without treatment and lowly expressed after treatment for $4 \mathrm{~h}$. Transcription of potassium channel AKT1-like (AKT1) underwent a continuous decline during the treatment process. Calmodulin 6 (CaM6), mitogen-activated protein kinase 15 (MAPK15), mitogen-activated protein kinase kinase 2 (MAP2K2), and mitogen-activated protein kinase kinase kinase 1 (MAP3K1) all showed a similar expression pattern. In the cloves, transcription of CDPK26 and AKT2 decreased until $4 \mathrm{~h}$ after treatment, followed by an evident increase. The expression of CML35 was downregulated after salt treatment and remained at a stable level with time extending. CIPK4 and CBL3 were lowly expressed after treatment for $12 \mathrm{~h}$, whereas KAT1 showed the lowest expression at $4 \mathrm{~h}$. The transcript levels of AKT1, CML35, NADH/NADPH oxidase, $M A P 2 K 2$, and $M A P 3 K 1$ showed an increase initially, followed by a continuous decrease since. No obvious difference was detected in CaM6 expression. In the roots, CDPK26 and MAP2K2 were lowly expressed after treatment for $1 \mathrm{~h}$, whereas CIPK4 and $N A D H / N A D P H$ oxidase showed the lowest mRNA abundance at $12 \mathrm{~h}$ after treatment. CML35 and AKT2 possessed a similar expression pattern. Transcription of KAT1, AKT1, and MAP3K1 increased to a high level in the early process of salt treatment, followed by a continuous decline. CML6 and MAPK15 kept relatively stable expression until $4 \mathrm{~h}$ after treatment (Figure 6).
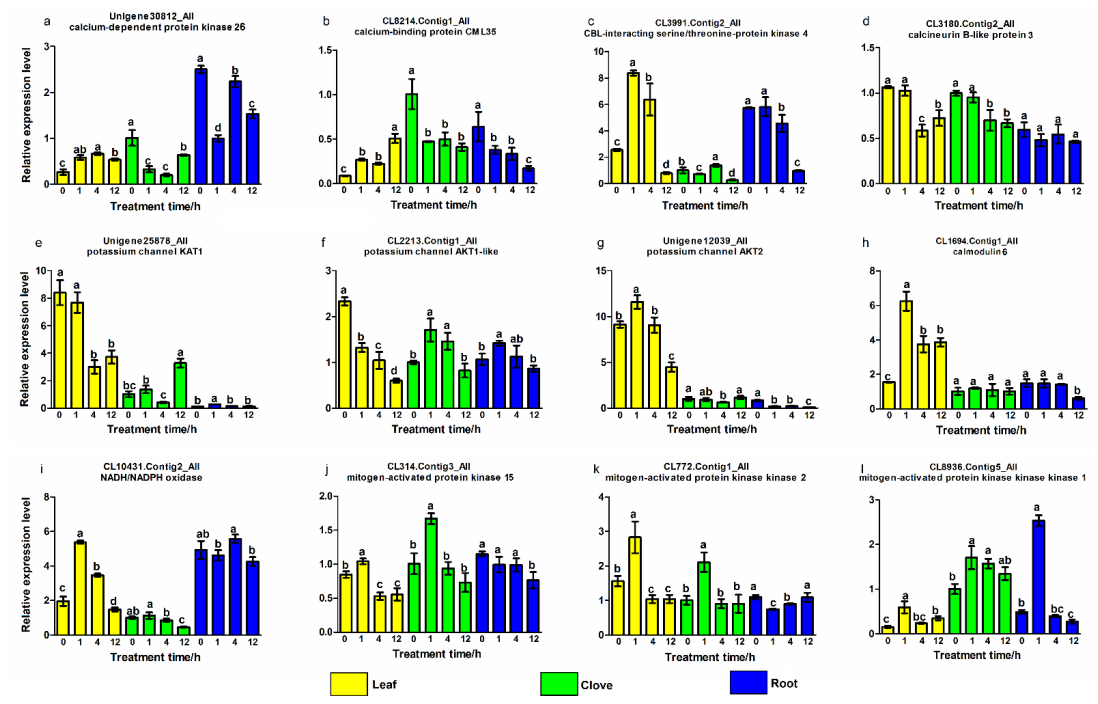

Figure 6. Expression patterns of genes involved in calcium signaling in garlic samples subjected to drought stress. Genes involved in calcium signaling include (a) calcium-dependent protein kinase 26 
(Unigene30812_All), (b) calcium-binding protein CML35 (CL8214.Contig1_All), (c) CBL-interacting serine/threonine-protein kinase 4, (d) calcineurin B-like protein 3 (CL3180.Contig2_All), (e) potassium channel KAT1 (Unigene25878_All), (f) potassium channel AKT1-like (CL2213.Contig1_All), (g) potassium channel AKT2 (Unigene12039_All), (h) calmodulin 6 (CL1694.Contig1_All), (i) NADH/NADPH oxidase (CL10431.Contig2_All), (j) mitogen-activated protein kinase 15 (CL314.Contig3_All), (k) mitogen-activated protein kinase kinase 2 (CL772.Contig1_All), and (1) mitogen-activated protein kinase kinase kinase 1 . The different lowercase letters in the same tissue represent a significant difference at the 0.05 level.

\section{Discussion}

Nowadays, the increasing prevalence of extreme weather or the environment has had a negative impact on crop production [42,43]. Drought damage is a critical element significantly influencing plant growth and yield formation. Understanding the molecular mechanism and mining stress resistance genes to carry on stress resistance breeding is an important way to deal with drought stress. Transcriptome sequencing makes it possible to obtain a large number of potential resistance genes. Here, 11,936 differentially expressed genes were generated in garlic plants exposed to simulated water stress. The findings from the present study would considerably increase the comprehension of dynamic changes in garlic under drought conditions.

It is recognized that water deficit may lead to alterations at the physiological and molecular levels, thus adapting to osmotic stress induced by water deficit. This process may be accompanied by a series of changes, including purine and phenylpropanoid metabolism [44], antioxidant defense system [45], flavonoid biosynthesis [46], and wax accumulation [47]. Here, we also found that phenylpropanoid biosynthesis and isoflavonoid biosynthesis were two of the most enriched KEGG pathways (Figure 4). Drought stress induced changes to the starch and sucrose metabolism, which is in accordance with the results observed in soybean [48]. Previous studies indicated that hormone biosynthesis and signaling were involved in plants exposed to water deficit. It is reported that OsMADS23 can promote ABA accumulation by activating biosynthesis genes to improve drought tolerance in rice [49]. Apple plants overexpressing $M d V Q 37$ showed reduced drought tolerance with altered SA homeostasis [50]. In this study, plant hormone signal transduction took part in the process of garlic plants responding to water deficit, suggesting a potential role of plant hormones in drought tolerance. Calcium signaling initiates the MAPK cascades to activate the downstream genes to protect plant cells [51,52]. Here, MAPK signaling pathway genes were also trapped in the response of garlic plants to water stress (Figure 4), further corroborating this view.

The ABA metabolism and signaling pathway is essential for drought stress responses. Numerous studies have indicated that alterations in the transcript levels of the genes in ABA metabolism and signal transduction may make difference to plant drought tolerance. Grapevine plants overexpressing 9-cis-epoxycarotenoid dioxygenase exhibited improved tolerance to drought [23]. Similarly, Arabidopsis plants harboring a gene encoding violaxanthin de-epoxidase from Cerasus humilis showed enhanced drought tolerance [53]. Mutation in a beta-carotene hydroxylase reduced zeaxanthin and ABA levels in rice, accompanied by decreased drought resistance [54]. The overexpression of ABF3 from Populus euphratica, encoding an $\mathrm{ABA}$ responsive element binding factor, showed higher photosynthetic activity and water-use efficiency in plants subjected to drought stress [55]. In this work, genes related to ABA biosynthesis and signaling were differentially expressed, suggesting a potential role of $\mathrm{ABA}$ in garlic plants under drought conditions.

Calcium is recognized as a second messenger to respond to external stimuli in plants. In trifoliate orange, PtrCDPK10 functioned in drought tolerance by decreasing ROS accumulation [56]. Similarly, the overexpression of wheat TaCIPK23 resulted in a developed root system and reduced water loss rate under drought conditions in Arabidopsis [57]. AKT1, KAT1, and AKT2 $\mathrm{K}^{+}$channels are important components in $\mathrm{Ca}^{2+}$ mediated $\mathrm{K}^{+}$uptake in guard cells, thus exerting influence on the performance under drought stress [58]. Barley 
plants with overexpressed $H v A K T 2$ showed increased $\mathrm{K}^{+}$uptake, $\mathrm{H}^{+}$homoeostasis and improved tolerance to drought stress [59]. MAPK cascade genes were demonstrated to function in the drought stress response in three cotton species, and similar results were also observed in Arabidopsis [60,61]. Here, the genes encoding calcium signaling and downstream components showed significant variation during the process of drought stress (Figure 6), indicating their potential roles in drought tolerance.

As mentioned above, both ABA and calcium signaling contribute to the response of garlic plants to water deficit. Indeed, sometimes, they coordinate to cope with environmental stimuli. Arabidopsis CPK6, a calcium-dependent protein kinase, can magnify ABA signaling by regulating ABA-responsive element-binding factors, resulting in improved tolerance under drought conditions [62]. Protein phosphatase $2 \mathrm{C}$, a negative regulator in ABA signaling, can interact with the calcium sensors CBL-CIPK and CDPK to control the slow anion channel type 1-S anion channel (SLAC1), thus influencing stomata opening under abiotic stresses [63].

In the present work, we characterize the dynamic changes of gene expression in $A$. sativum under water deficit based on transcriptome sequencing. A total of 31,404 predicted coding sequences and 11,936 differentially expressed genes were generated. Functional analysis indicated that water deficit in garlic affects a number of genes involved in different biological and physiological processes. Genes involved in abscisic acid metabolism and calcium signaling were extensively investigated, shedding new light on the work to improve drought tolerance.

Supplementary Materials: The following are available online at https:/ / www.mdpi.com/article / 10.3390/app12052440/s1, Figure S1: Results of BUSCO assembly evaluation, Figure S2: Species distribution annotated by NR database, Figure S3: Gene ontology classification of assembled unigenes identified in garlic under water stress. The $x$-axis indicates the corresponding number of unigenes, and the $y$-axis indicates the GO function group, Figure S4: KOG function annotation of unigenes. A total of 31,955 unigenes were annotated to 25 categories, Figure S5: KEGG classification of unigenes. The $x$-axis indicates the corresponding number of unigenes, and the $y$-axis indicates the KEGG function classification, Table S1: Differentially expressed genes involved in abscisic acid metabolism and signaling, Table S2: Correlation between the expression levels of genes in abscisic acid metabolism and signaling and digital gene expression, Table S3: Differentially expressed genes involved in calcium signaling pathway, Table S4: Correlation between the expression levels of genes in calcium signaling and digital gene expression.

Author Contributions: Conceptualization, G.-L.W. and J.T.; methodology, G.-L.W.; software, L.-Y.L.; validation, G.-L.W., X.-Q.R. and A.-S.X.; formal analysis, G.-L.W.; investigation, G.-L.W.; resources, G.-L.W.; data curation, Q.-Z.W.; writing-original draft preparation, G.-L.W.; writing-review and editing, G.-L.W.; visualization, G.-L.W.; supervision, J.T.; project administration, G.-L.W. and J.T.; funding acquisition, G.-L.W. and J.T. All authors have read and agreed to the published version of the manuscript.

Funding: This research was funded by the Key Laboratory Project of Qinghai Science \& Technology Department (Grant No. 2020-ZJ-Y02), the Open Project of Qinghai Key Laboratory of Vegetable Genetics and Physiology (Grant No. 2020-SCSYS-01), and Natural Science Foundation of China (Grant No. 31760568).

Institutional Review Board Statement: Not applicable.

Informed Consent Statement: Not applicable.

Data Availability Statement: Data are contained within the article and Supplementary Materials.

Conflicts of Interest: The authors declare that there are no conflicting interest regarding the publication of this work. 


\section{References}

1. Wang, H.S.; Zhu, Z.J.; Feng, Z.; Zhang, S.G.; Yu, C. Antisense-mediated depletion of GMPase gene expression in tobacco decreases plant tolerance to temperature stresses and alters plant development. Mol. Biol. Rep. 2012, 39, 10413-10420. [CrossRef] [PubMed]

2. Wang, H.S.; Yu, C.; Tang, X.F.; Zhu, Z.J.; Ma, N.N.; Meng, Q.W. A tomato endoplasmic reticulum (ER)-type omega-3 fatty acid desaturase (LeFAD3) functions in early seedling tolerance to salinity stress. Plant Cell Rep. 2014, 33, 131-142. [CrossRef] [PubMed]

3. Wang, X.; Komatsu, S. Proteomic approaches to uncover the flooding and drought stress response mechanisms in soybean. J. Proteom. 2018, 172, 201-215. [CrossRef] [PubMed]

4. Long, Y.; Liang, F.; Zhang, J.; Xue, M.; Zhang, T.; Pei, X. Identification of drought response genes by digital gene expression (DGE) analysis in Caragana korshinskii Kom. Gene 2020, 725, 144170. [CrossRef]

5. Liu, Y.; Zhang, P.; Li, M.; Chang, L.; Cheng, H.; Chai, S.; Yang, D. Dynamic responses of accumulation and remobilization of water soluble carbohydrates in wheat stem to drought stress. Plant Physiol. Biochem. 2020, 155, 262-270. [CrossRef]

6. Joukhadar, R.; Thistlethwaite, R.; Trethowan, R.; Keeble-Gagnère, G.; Hayden, M.J.; Ullah, S.; Daetwyler, H.D. Meta-analysis of genome-wide association studies reveal common loci controlling agronomic and quality traits in a wide range of normal and heat stressed environments. Theor. Appl. Genet. 2021, 134, 2113-2127. [CrossRef]

7. Daszkowska-Golec, A.; Collin, A.; Sitko, K.; Janiak, A.; Kalaji, H.M.; Szarejko, I. Genetic and physiological dissection of photosynthesis in barley exposed to drought stress. Int. J. Mol. Sci. 2019, 20, 6341. [CrossRef]

8. Chen, D.; He, L.; Lin, M.; Jing, Y.; Liang, C.; Liu, H.; Gao, J.; Zhang, W.; Wang, M. A ras-related small GTP-binding protein, RabE1c, regulates stomatal movements and drought stress responses by mediating the interaction with ABA receptors. Plant Sci. 2021, 306, 110858. [CrossRef]

9. Knipfer, T.; Bambach, N.; Hernandez, M.I.; Bartlett, M.K.; Sinclair, G.; Duong, F.; Kluepfel, D.A.; McElrone, A.J. Predicting stomatal closure and turgor loss in woody plants using predawn and midday water potential. Plant Physiol. 2020, 184, 881-894. [CrossRef]

10. Bai, Y.; Xiao, S.; Zhang, Z.; Zhang, Y.; Sun, H.; Zhang, K.; Wang, X.; Bai, Z.; Li, C.; Liu, L. Melatonin improves the germination rate of cotton seeds under drought stress by opening pores in the seed coat. PeerJ 2020, 8, e9450. [CrossRef]

11. Hwang, K.; Susila, H.; Nasim, Z.; Jung, J.Y.; Ahn, J.H. Arabidopsis ABF3 and ABF4 transcription factors act with the NF-YC complex to regulate SOC1 expression and mediate drought-accelerated flowering. Mol. Plant 2019, 12, 489-505. [CrossRef] [PubMed]

12. Jiang, W.; Li, N.; Zhang, D.; Meinhardt, L.; Cao, B.; Li, Y.; Song, L. Elevated temperature and drought stress significantly affect fruit quality and activity of anthocyanin-related enzymes in jujube (Ziziphus jujuba Mill. cv. 'Lingwuchangzao'). PLoS ONE 2020, 15, e0241491. [CrossRef] [PubMed]

13. Azzouz-Olden, F.; Hunt, A.G.; Dinkins, R. Transcriptome analysis of drought-tolerant sorghum genotype SC56 in response to water stress reveals an oxidative stress defense strategy. Mol. Biol. Rep. 2020, 47, 3291-3303. [CrossRef] [PubMed]

14. He, F.; Steige, K.A.; Kovacova, V.; Göbel, U.; Bouzid, M.; Keightley, P.D.; Beyer, A.; De Meaux, J. Cis-regulatory evolution spotlights species differences in the adaptive potential of gene expression plasticity. Nat. Commun. 2021, 12, 3376. [CrossRef] [PubMed]

15. Diouf, I.; Albert, E.; Duboscq, R.; Santoni, S.; Bitton, F.; Gricourt, J.; Causse, M. Integration of QTL, transcriptome and polymorphism studies reveals candidate genes for water stress response in tomato. Genes 2020, 11, 900. [CrossRef] [PubMed]

16. Kumar, S.; Ayachit, G.; Sahoo, L. Screening of mungbean for drought tolerance and transcriptome profiling between droughttolerant and susceptible genotype in response to drought stress. Plant Physiol. Biochem. 2020, 157, 229-238. [CrossRef] [PubMed]

17. Guo, J.; Li, C.; Zhang, X.; Li, Y.; Zhang, D.; Shi, Y.; Song, Y.; Li, Y.; Yang, D.; Wang, T. Transcriptome and GWAS analyses reveal candidate gene for seminal root length of maize seedlings under drought stress. Plant Sci. 2020, 292, 110380. [CrossRef]

18. Liu, J.; Deng, J.L.; Tian, Y. Transcriptome sequencing of the apricot (Prunus armeniaca L.) and identification of differentially expressed genes involved in drought stress. Phytochemistry 2020, 171, 112226. [CrossRef]

19. Mahmood, T.; Khalid, S.; Abdullah, M.; Ahmed, Z.; Shah, M.K.; Ghafoor, A.; Du, X. Insights into drought stress signaling in plants and the molecular genetic basis of cotton drought tolerance. Cells 2020, 9, 105. [CrossRef]

20. Chen, Y.; Li, C.; Yi, J.; Yang, Y.; Lei, C.; Gong, M. Transcriptome response to drought, rehydration and re-dehydration in potato. Int. J. Mol. Sci. 2020, 21, 159. [CrossRef]

21. Li, M.Q.; Yang, J.; Wang, X.; Li, D.X.; Zhang, C.B.; Tian, Z.H.; You, M.H.; Bai, S.Q.; Lin, H.H. Transcriptome profiles identify the common responsive genes to drought stress in two Elymus species. J. Plant Physiol. 2020, 250, 153183. [CrossRef] [PubMed]

22. An, X.; Jin, G.; Luo, X.; Chen, C.; Li, W.; Zhu, G. Transcriptome analysis and transcription factors responsive to drought stress in Hibiscus cannabinus. PeerJ 2020, 8, e8470. [CrossRef] [PubMed]

23. He, R.; Zhuang, Y.; Cai, Y.; Agüero, C.B.; Liu, S.; Wu, J.; Deng, S.; Walker, M.A.; Lu, J.; Zhang, Y. Overexpression of 9-cisepoxycarotenoid dioxygenase cisgene in grapevine increases drought tolerance and results in pleiotropic effects. Front. Plant Sci. 2018, 9, 970. [CrossRef] [PubMed]

24. Zhang, Y.; Liu, X.; Ruan, J.; Zhuang, X.; Zhang, X.; Li, Z. Phytochemicals of garlic: Promising candidates for cancer therapy. Biomed. Pharmacother. 2020, 123, 109730. [CrossRef]

25. Liu, P.; Weng, R.; Xu, Y.; Pan, Y.; Wang, B.; Qian, Y.; Qiu, J. Distinct quality changes of garlic bulb during growth by metabolomics analysis. J. Agric. Food Chem. 2020, 68, 5752-5762. [CrossRef] 
26. Mukarram, M.; Choudhary, S.; Kurjak, D.; Petek, A.; Khan, M.M.A. Drought: Sensing, signalling, effects and tolerance in higher plants. Physiol. Plant. 2021, 172, 1291-1300. [CrossRef]

27. Edel, K.H.; Kudla, J. Integration of calcium and ABA signaling. Curr. Opin. Plant Biol. 2016, 33, 83-91. [CrossRef]

28. Brown, J.; Pirrung, M.; McCue, L.A. FQC Dashboard: Integrates FastQC results into a web-based, interactive, and extensible FASTQ quality control tool. Bioinformatics 2017, 33, 3137-3139. [CrossRef]

29. Chen, Y.; Chen, Y.; Shi, C.; Huang, Z.; Zhang, Y.; Li, S.; Li, Y.; Ye, J.; Yu, C.; Li, Z.; et al. SOAPnuke: A MapReduce accelerationsupported software for integrated quality control and preprocessing of high-throughput sequencing data. Gigascience 2018, 7, gix120. [CrossRef]

30. Grabherr, M.G.; Haas, B.J.; Yassour, M.; Levin, J.; Thompson, D.A.; Amit, I.; Adiconis, X.; Fan, L.; Raychowdhury, R.; Zeng, Q.; et al. Full-length transcriptome assembly from RNA-Seq data without a reference genome. Nat. Biotechnol. 2011, $29,644-652$. [CrossRef]

31. Pertea, G.; Huang, X.; Liang, F.; Antonescu, V.; Sultana, R.; Karamycheva, S.; Lee, Y.; White, J.; Cheung, F.; Parvizi, B.; et al. TIGR Gene Indices clustering tools (TGICL): A software system for fast clustering of large EST datasets. Bioinformatics 2003, 19, 651-652. [CrossRef] [PubMed]

32. Seppey, M.; Manni, M.; Zdobnov, E.M. BUSCO: Assessing genome assembly and annotation completeness. Methods Mol. Biol. 2019, 1962, 227-245. [PubMed]

33. Tatusov, R.L.; Fedorova, N.D.; Jackson, J.D.; Jacobs, A.R.; Kiryutin, B.; Koonin, E.V.; Krylov, D.M.; Mazumder, R.; Mekhedov, S.L.; Nikolskaya, A.N.; et al. The COG database: An updated version includes eukaryotes. BMC Bioinform. 2003, 4, 41. [CrossRef] [PubMed]

34. Kanehisa, M.; Araki, M.; Goto, S.; Hattori, M.; Hirakawa, M.; Itoh, M.; Katayama, T.; Kawashima, S.; Okuda, S.; Tokimatsu, T.; et al. KEGG for linking genomes to life and the environment. Nucleic Acids Res. 2008, 36, D480-D484. [CrossRef]

35. Boratyn, G.M.; Camacho, C.; Cooper, P.S.; Coulouris, G.; Fong, A.; Ma, N.; Madden, T.L.; Matten, W.T.; McGinnis, S.D.; Merezhuk, Y.; et al. BLAST: A more efficient report with usability improvements. Nucleic Acids Res. 2013, 41, W29-W33. [CrossRef]

36. Ye, J.; Fang, L.; Zheng, H.; Zhang, Y.; Chen, J.; Zhang, Z.; Wang, J.; Li, S.; Li, R.; Bolund, L.; et al. WEGO: A web tool for plotting GO annotations. Nucleic Acids Res. 2006, 34, W293-W297. [CrossRef]

37. Conesa, A.; Götz, S.; García-Gómez, J.M.; Terol, J.; Talón, M.; Robles, M. Blast2GO: A universal tool for annotation, visualization and analysis in functional genomics research. Bioinformatics 2005, 21, 3674-3676. [CrossRef]

38. Langmead, B.; Salzberg, S.L. Fast gapped-read alignment with Bowtie 2. Nat. Methods 2012, 9, 357-359. [CrossRef]

39. Li, B.; Dewey, C.N. RSEM: Accurate transcript quantification from RNA-Seq data with or without a reference genome. BMC Bioinform. 2011, 12, 323. [CrossRef]

40. Audic, S.; Claverie, J.M. The significance of digital gene expression profiles. Genome Res. 1997, 7, 986-995. [CrossRef]

41. Wang, G.; Tian, C.; Wang, Y.; Wan, F.; Hu, L.; Xiong, A.; Tian, J. Selection of reliable reference genes for quantitative RT-PCR in garlic under salt stress. PeerJ 2019, 7, e7319. [CrossRef] [PubMed]

42. Wang, H.S.; Yu, C.; Zhu, Z.J.; Yu, X.C. Overexpression in tobacco of a tomato GMPase gene improves tolerance to both low and high temperature stress by enhancing antioxidation capacity. Plant Cell Rep. 2011, 30, 1029-1040. [CrossRef] [PubMed]

43. Wang, H.S.; Yu, C.; Tang, X.F.; Wang, L.Y.; Dong, X.C.; Meng, Q.W. Antisense-mediated depletion of tomato endoplasmic reticulum omega-3 fatty acid desaturase enhances thermal tolerance. J. Integr. Plant Biol. 2010, 52, 568-577. [CrossRef]

44. Zhang, C.; Chen, J.; Huang, W.; Song, X.; Niu, J. Transcriptomics and metabolomics reveal purine and phenylpropanoid metabolism response to drought stress in dendrobium sinense, an endemic orchid species in Hainan Island. Front. Genet. 2021, 12, 692702. [CrossRef] [PubMed]

45. Imran, M.; Latif Khan, A.; Shahzad, R.; Aaqil Khan, M.; Bilal, S.; Khan, A.; Kang, S.M.; Lee, I.J. Exogenous melatonin induces drought stress tolerance by promoting plant growth and antioxidant defence system of soybean plants. AoB Plants 2021, 13, plab026. [CrossRef] [PubMed]

46. Kubra, G.; Khan, M.; Munir, F.; Gul, A.; Shah, T.; Hussain, A.; Caparrós-Ruiz, D.; Amir, R. Expression characterization of flavonoid biosynthetic pathway genes and transcription factors in peanut under water deficit conditions. Front. Plant Sci. 2021, 12, 680368 [CrossRef]

47. Wen, X.; Geng, F.; Cheng, Y.; Wang, J. Ectopic expression of CsMYB30 from Citrus sinensis enhances salt and drought tolerance by regulating wax synthesis in Arabidopsis thaliana. Plant Physiol. Biochem. 2021, 166, 777-788. [CrossRef]

48. Du, Y.; Zhao, Q.; Chen, L.; Yao, X.; Zhang, H.; Wu, J.; Xie, F. Effect of drought stress during soybean R2-R6 growth stages on sucrose metabolism in leaf and seed. Int. J. Mol. Sci. 2020, 21, 618. [CrossRef]

49. Li, X.; Yu, B.; Wu, Q.; Min, Q.; Zeng, R.; Xie, Z.; Huang, J.A.O. OsMADS23 phosphorylated by SAPK9 confers drought and salt tolerance by regulating ABA biosynthesis in rice. PLoS Genet. 2021, 17, e1009699. [CrossRef]

50. Dong, Q.; Duan, D.; Zheng, W.; Huang, D.; Wang, Q.; Yang, J.; Liu, C.; Li, C.; Gong, X.; Li, C.; et al. Overexpression of MdVQ37 reduces drought tolerance by altering leaf anatomy and SA homeostasis in transgenic apple. Tree Physiol. 2021, 42, 160-174. [CrossRef]

51. Shanker, A.K.; Maheswari, M.; Yadav, S.K.; Desai, S.; Bhanu, D.; Attal, N.B.; Venkateswarlu, B. Drought stress responses in crops. Funct. Integr. Genom. 2014, 14, 11-22. [CrossRef] [PubMed]

52. Zhu, J.K. Abiotic stress signaling and responses in plants. Cell 2016, 167, 313-324. [CrossRef] [PubMed] 
53. Sun, L.N.; Wang, F.; Wang, J.W.; Sun, L.J.; Gao, W.R.; Song, X.S. Overexpression of the ChVDE gene, encoding a violaxanthin de-epoxidase, improves tolerance to drought and salt stress in transgenic Arabidopsis. 3 Biotech 2019, 9, 197. [CrossRef] [PubMed]

54. Du, H.; Wang, N.; Cui, F.; Li, X.; Xiao, J.; Xiong, L. Characterization of the $\beta$-carotene hydroxylase gene DSM2 conferring drought and oxidative stress resistance by increasing xanthophylls and abscisic acid synthesis in rice. Plant Physiol. 2010, 154, 1304-1318. [CrossRef]

55. Yang, Y.; Li, H.G.; Wang, J.; Wang, H.L.; He, F.; Su, Y.; Zhang, Y.; Feng, C.H.; Niu, M.; Li, Z.; et al. ABF3 enhances drought tolerance via promoting ABA-induced stomatal closure by directly regulating ADF5 in Populus euphratica. J. Exp. Bot. 2020, 71, 7270-7285. [CrossRef]

56. Meng, L.; Zhang, Q.; Yang, J.; Xie, G.; Liu, J.H. PtrCDPK10 of Poncirus trifoliata functions in dehydration and drought tolerance by reducing ROS accumulation via phosphorylating PtrAPX. Plant Sci. 2020, 291, 110320. [CrossRef]

57. Cui, X.Y.; Du, Y.T.; Fu, J.D.; Yu, T.F.; Wang, C.T.; Chen, M.; Chen, J.; Ma, Y.Z.; Xu, Z.S. Wheat CBL-interacting protein kinase 23 positively regulates drought stress and ABA responses. BMC Plant Biol. 2018, 18, 93. [CrossRef]

58. Ivashikina, N.; Deeken, R.; Fischer, S.; Ache, P.; Hedrich, R. AKT2/3 subunits render guard cell $\mathrm{K}^{+}$channels Ca ${ }^{2+}$ sensitive. J. Gen. Physiol. 2005, 125, 483-492. [CrossRef]

59. Feng, X.; Liu, W.; Qiu, C.W.; Zeng, F.; Wang, Y.; Zhang, G.; Chen, Z.H.; Wu, F. HvAKT2 and HvHAK1 confer drought tolerance in barley through enhanced leaf mesophyll $\mathrm{H}^{+}$homoeostasis. Plant Biotechnol. J. 2020, 18, 1683-1696. [CrossRef]

60. Chen, L.; Sun, H.; Wang, F.; Yue, D.; Shen, X.; Sun, W.; Zhang, X.; Yang, X. Genome-wide identification of MAPK cascade genes reveals the GhMAP3K14-GhMKK11-GhMPK31 pathway is involved in the drought response in cotton. Plant Mol. Biol. 2020, 103, 211-223. [CrossRef]

61. Li, Y.; Cai, H.; Liu, P.; Wang, C.; Gao, H.; Wu, C.; Yan, K.; Zhang, S.; Huang, J.; Zheng, C. Arabidopsis MAPKKK18 positively regulates drought stress resistance via downstream MAPKK3. Biochem. Biophys. Res. Commun. 2017, 484, 292-297. [CrossRef] [PubMed]

62. Zhang, H.; Liu, D.; Yang, B.; Liu, W.Z.; Mu, B.; Song, H.; Chen, B.; Li, Y.; Ren, D.; Deng, H.; et al. Arabidopsis CPK6 positively regulates $\mathrm{ABA}$ signaling and drought tolerance through phosphorylating ABA-responsive element-binding factors. J. Exp. Bot. 2020, 71, 188-203. [CrossRef] [PubMed]

63. Xiong, T.; Tan, Q.; Li, S.; Mazars, C.; Galaud, J.P.; Zhu, X. Interactions between calcium and ABA signaling pathways in the regulation of fruit ripening. J. Plant Physiol. 2021, 256, 153309. [CrossRef] [PubMed] 